
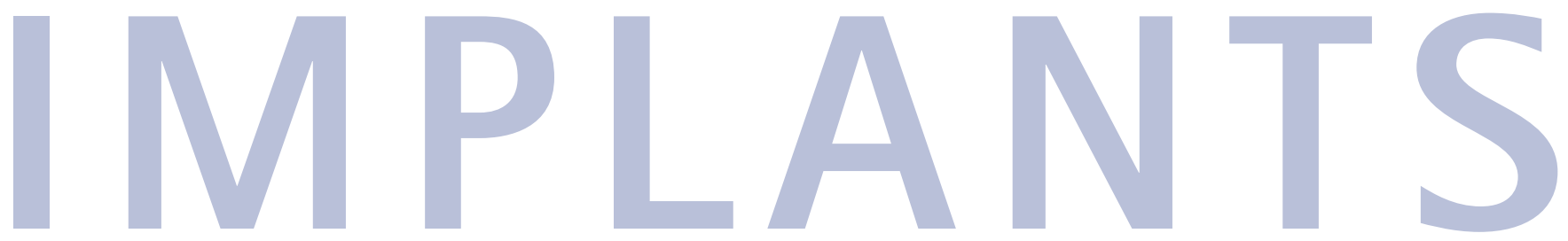

\section{Reducing bone loss}

Euroklee's Implant Of Collagen can be used following extractions where significant bone loss may have occured, especial-

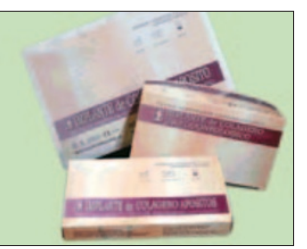
ly if the patient experiences an infected socket according to the company.

The risk of significant bone loss can be minimised by ensuring, wherever possible, that a healthy blood clot is formed and rapid healing ensues. An appropriate quantity is packed into the bleeding socket immediately after the extraction and this stimulates immediate haemostasis.

The company claims that while the product's hydrophilic nature and porous structure facilitates the rapid ingress of leukocytes and granulation tissue, over a period of time the collagen is resorbed and replaced with new bone tissue which maintains the bone height.

Reader response number 54

\section{Self-guiding implant}

The Conical Seal Design from Astra Tech has been created to provide a tight, firm connection between the implant and the abutment.

The self-guiding nature of the product also eliminates the need for a control x-ray upon abutment connection and the safe mechanical performance of this design has been proved to greatly improve the implant's long-term performance, according to Astra Tech.

Implants are delivered pre-mounted in a colour coded package which can simplify identification, handling and installation.

Reader response number 55

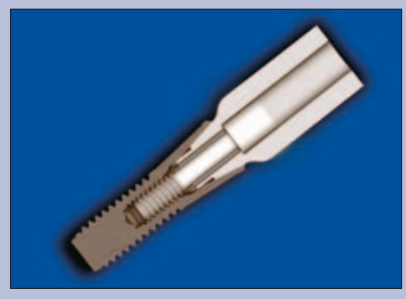

\section{Slimline jet polisher}

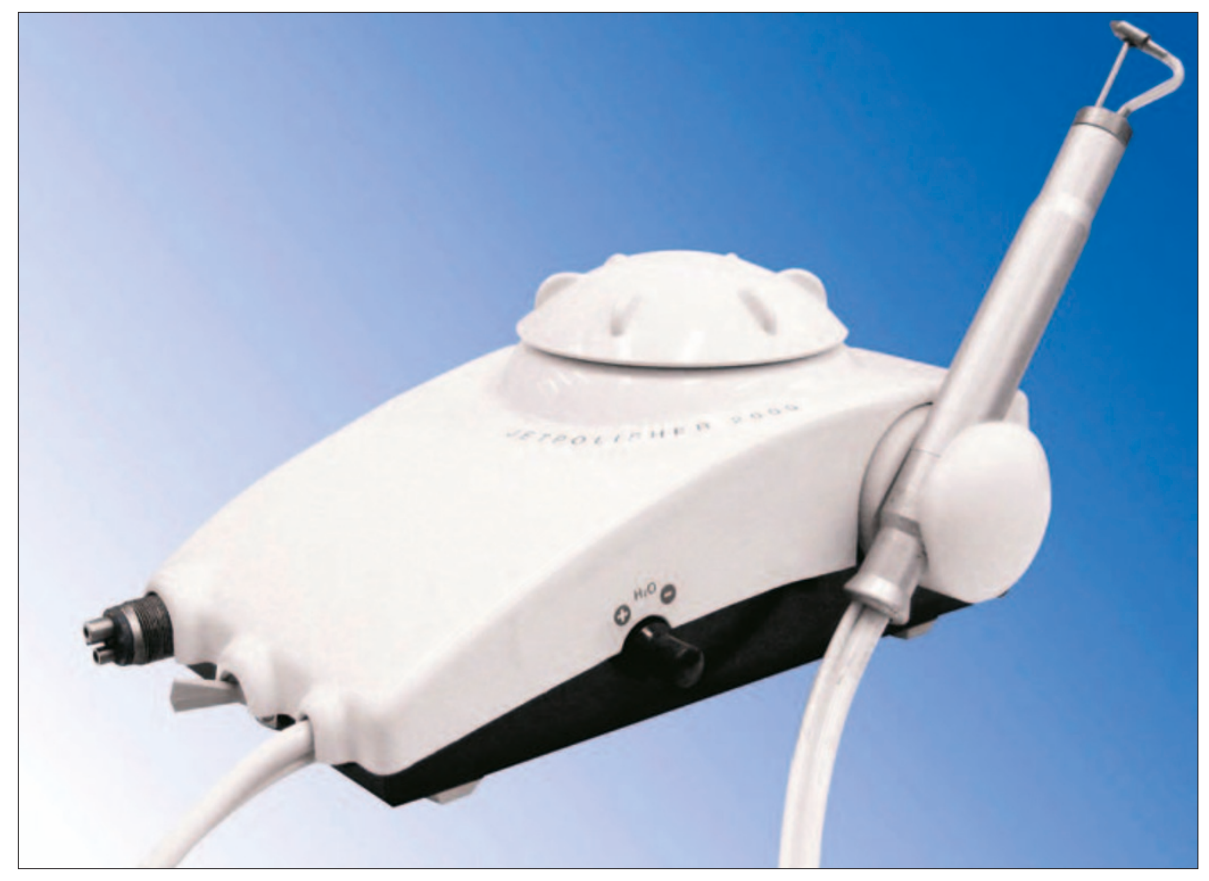

The slimline Deldent JetPolisher air polishing unit can enable dentists to clean around hard to reach areas including implant superstructures according to Minerva Dental.

Its patented homogeneous stream technology (HST) mixes a sodium bicarbonate

stream with water within the spray head to produce an homogenous polishing stream.

The single nozzle system means that there is no build up of anhydrous sodium bicarbonate associated with separate nozzle systems, reducing clogging.

Reader response number 56

\title{
Additions to implant range
}

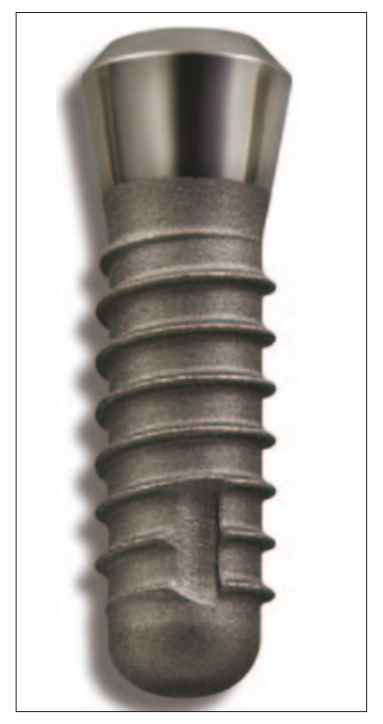

Lifecore Thin Boy and Fat Boy Implants are the new larger and smaller diameter additions to Lifecore's existing Stage 1 implant range. Fat Boy $5.5 \mathrm{~mm}$ diameter implants are available in four lengths $(8 \mathrm{~mm}, 10 \mathrm{~mm}, 12 \mathrm{~mm}$ and $14 \mathrm{~mm})$ and in two collar heights, 1.8 and $2.8 \mathrm{~mm}$ while the Fat Boy $6.3 \mathrm{~mm}$ diameter implants are available in two lengths ( 8 and $10 \mathrm{~mm}$ ) and in two collar heights 1.8 and $2.8 \mathrm{~mm}$. Both use the Wide Diameter restorative component.

The Thin Boy 3.3mm diameter implants are also available in four lengths $(8 \mathrm{~mm}, 10 \mathrm{~mm}, 12 \mathrm{~mm}$ and $14 \mathrm{~mm})$. They use the Regular Diameter restorative component and are available in two collar heights 1.8 and $2.8 \mathrm{~mm}$. Also available from Healthco Ltd are Quick Impression Caps for use with Lifecore Stage I and ITI Straumann implants. Each Quick Cap is colour coded to the appropriate Lifecore cement on crown abutment, which are interchangeable with Straumann ITI abutments.

Reader response number 57 


\section{Implant kits for patients}

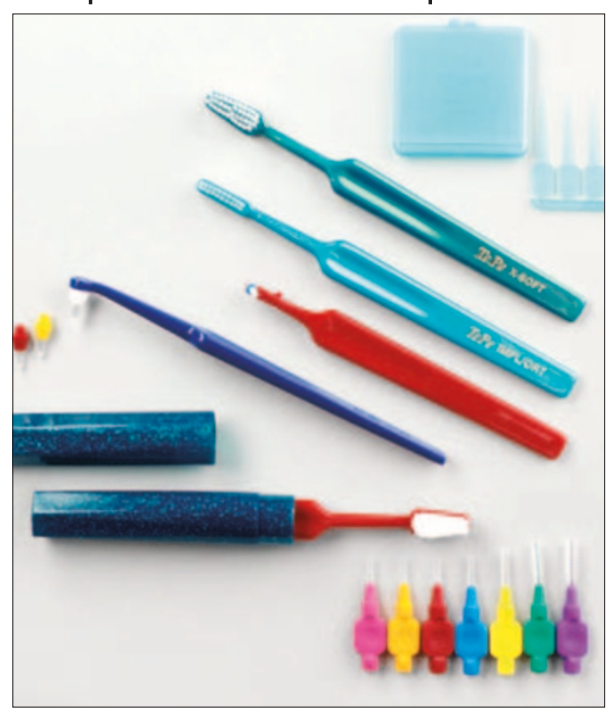

Molar's new Implant Kit contains a comprehensive range of products specifically for use by the implant patient.

It includes a special care toothbrush and a TePe Select extra soft toothbrush for general oral hygiene. For specific cleaning around implant abutment posts, the implant and interspace can be used.

Sample packs of the TePe interdental brushes and proximal brush are included as well as a toothbrush travel case which can be used for any of the TePe toothbrushes. Also featured are plastic interdental sticks and Proxi-Floss.

The Implant Kit is available exclusively from Molar for $£ 9.90$ each with a minimum order quantity of three packs.

Reader response number 58

\section{Three step implant system}

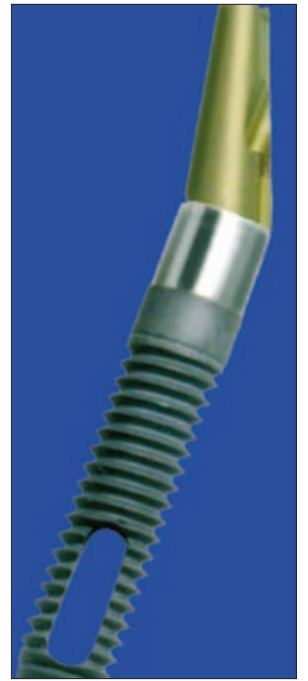

The Unipost Three Step Implant System is designed to maximize the use of available bone and create maximum surface contact for compressive bone loading when the implants are brought into function.

This includes D Fin Implants which are particularly indicated for use after 'bone expansion' using osteotomes in edentulous regions with inadequate bone for conventional screw implants.

Both Unipost's D Fin and conventional screw implants are manufactured from Tivalloy, containing 90 per cent titanium, 6 per cent aluminium and 4 per cent vanadium.

With the Unipost Three Step Implant System the implants are placed transmucosally so that the head is level with the gingival crest and not buried, which avoids the need for a second stage of surgery to expose the implant for abutment placement.

This design also ensures that there is no sub-gingival joint between the implant and abutment to harbour toxins and bacteria. Reader response number 59

\section{Solutions to bone loss}

The Osteogenic Distractor can be a solution to bone loss resulting from extractions, according to General Medical. Requiring relatively minor surgical intervention they enable the surgeon to rebuild missing ridges in a predictable manor employing principles associated with orthodontic expansion screws.

Following a conservative osteotomy of the cortical bone a dissected bone block is created in situ. The free bone block is then held in place using the Osteogenic Distractor and appropriate microscrews.

Using a hand key the central rod of the Distractor is activated, causing the plates to move away from each other which sets the distraction process in motion, during which the micro-gap is filled with new bone tissue. This procedure is repeated

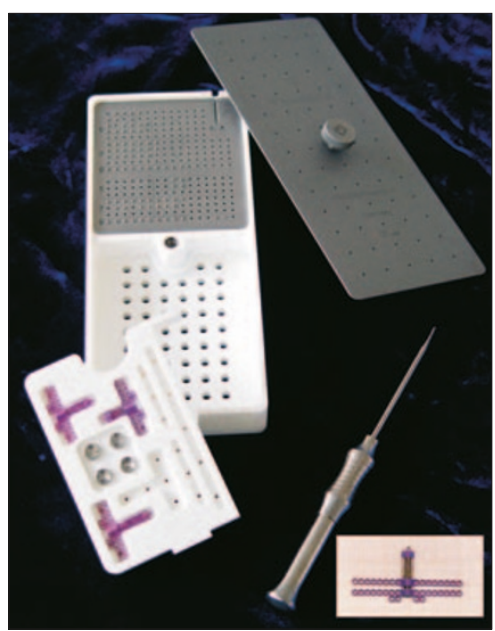
at regular intervals until the desired new ridge height is achieved and the distraction process can be used to rebuild ridges up to $15 \mathrm{~mm}$ in height. The product is available from General Medical within Haley Implant Accessory Catalogue.

Reader response number 60 